\title{
El primer asesinato político en democracia: Osman Yeomans Osorio. Análisis y simbolismo político del caso
}

\author{
The first political murder in democracy: Osman Yeomans Osorio.
}

Analysis and political symbolism of the case

\author{
Matías Alvarado Leyton*
}

\begin{abstract}
Resumen: La muerte de Osman Bernardo Yeomans Osorio, el 27 de junio de 1990, es considerado el primer asesinato político tras la vuelta a la democracia en Chile. Tiroteado por un carabinero, este hecho da cuenta de la exención de castigo con que las Fuerzas Armadas y de Orden y Seguridad contaron en el gobierno de Patricio Aylwin. Esto permite sostener la existencia de una conciencia de impunidad, poner en entredicho la alegría del "No" y ver la presencia de ciertas continuidades con la dictadura cívico-militar chilena.
\end{abstract}

Palabras clave: Asesinato político, Patricio Aylwin, memoria, conciencia de impunidad.

Abstract: The death of Osman Bernardo Yeomans Osorio, on June 27, 1990, is considered the first political murder after the return of democracy in Chile. Shot by a policeman, this fact exhibits the exemption of punishment of the Armed, Order and Security Forces in the government of Patricio Aylwin. This allows to sustaining the existence of a consciousness of impunity, questioning the joy the "No" and seeing the presence of some continuities with the Chilean civicmilitary dictatorship.

Keywords: Political murder, Patricio Aylwin's government, memory, consciousness of impunity.

Recibido: 7 agosto 2018 Aceptado: 13 octubre 2018

"Creo más apropiado sostener que la transición a la democracia debía considerarse terminada en cuanto desapareciera todo riesgo de regresión autoritaria, lo que ciertamente nadie habría osado afirmar al 11 de marzo de 1990", señalaba Edgardo Boeninger en Democracia en Chile. Lecciones para la gobernabilidad, publicado en 1997. Posiblemente, el propio Boeninger tenía impresiones similares después de aquella fecha, ya que él, estando a la cabeza del Ministerio Secretaría General de la Presidencia durante todo el gobierno de Patricio Aylwin, tuvo que haberse enterado, al menos por la prensa, de los hechos ocurridos entre el 26 y 27 de junio de 1990, fecha última en que muere Osman Bernardo Yeomans Osorio, el primer asesinado político tras la vuelta a la democracia en el país.

\footnotetext{
* Chileno. Licenciado en Historia y Magister en Historia (C) por la Pontificia Universidad Católica de Chile. Doctorando en Historia por la Universidad San Sebastián de Chile. Realiza su tesis de doctorado acerca de las políticas culturales durante la dictadura cívico-militar chilena, 1973-1989. matias.alvaradoleyton@gmail.com.

${ }^{1}$ Edgardo Boeninger, Democracia en Chile. Lecciones para la gobernabilidad, Santiago, Editorial Andrés Bello, 1997, 380.
} 
Es curioso que el homicidio de Yeomans no haya cobrado la relevancia que uno supondría. Si bien, tuvo cobertura por parte de distintos medios de comunicación, lo cierto es que la figura de Yeomans comienza a perderse rápidamente dentro de la vorágine de la opinión pública, es más, ni siquiera los partidos políticos más sensibles a este hecho hacen mucho al respecto por aquellos años. Menos aún las distintas disciplinas académicas, donde la figura de Yeomans apenas ha sido mencionada y muchas veces con faltas a la realidad misma del suceso ${ }^{2}$. Pareciera que todos realmente se acogieron a la idea de que la democracia volvió el 11 de marzo de 1990, dejando atrás todo el pasado y, con éste, a Yeomans. Sin embargo, como señalaba el propio Boeninger con posterioridad, mientras existiera algún riesgo de volver a una dictadura, la transición no había acabado. Lo ocurrido con este joven obrero metalúrgico, de entonces 23 años, asesinado de un disparo directo a la cabeza por un carabinero uniformado, es un claro ejemplo de esto. Es más, el asesinato de Yeomans cobra un inusitado matiz si se tiene en consideración que éste ocurrió con un curioso fondo: el rayado de un mural por el natalicio de Salvador Allende.

Pese a los cuestionamientos de distinto tipo en que se podría incurrir, lo cierto es que estos no son parte del quehacer de la disciplina histórica. De este modo, este artículo analiza el primer asesinato político ocurrido tras la vuelta a la democracia, un hecho casi desapercibido en la historia del país, pero con una considerable significancia tanto cultural como política. En miras a esto, este artículo se divide en tres partes. Primeramente, se estudia el hecho mismo, entendiéndolo en toda su particularidad, a través de la reconstrucción de éste por medio de la documentación dejada tras de sí y el testimonio de quienes le sobrevivieron. Luego de esto, se inserta el hecho en un contexto más grande, particularmente con implicancias que son posibles de avizorar respecto al devenir de ciertas aristas de la historia política del país. Finalmente, se toman ciertas consideraciones teóricas que vale la pena tener en cuenta al analizar el hecho, desde la ritualidad política involucrada, especialmente en un contexto tan álgido como el que se vivía en aquel momento.

Por sus propias características, este artículo no solo debe ser entendido como un esfuerzo por la recuperación de la memoria del país al inicio de su transición democrática, relevando el caso de un joven militante, sino también como parte de la Historia del Tiempo Presente (HTP). Tal y como han señalado distintos historiadores abocados a su estudio, más que una nueva periodización, la HTP es una disposición actualizada de la disciplina ante la realidad que actualmente atraviesa. Si bien, sus características son muchas más, parece que esta definición, aunque vaga, permite dar cuenta de una verdad: la HTP es, por sobre cualquier cosa, una forma de entender y trabajar con los hechos recientes, con lo coetáneo, destacando precisamente la importancia de la coetaneidad y no así de la contemporaneidad $^{3}$. Respecto a esto, el primer asesinado político tras la vuelta a la democracia llama

2 Véase Victoria Zapata, Cárcel de alta seguridad. Inbumanidad, represión y rebeldía, Santiago, Editorial Mare Nostrum, 2005, 146. El homicidio de Yeomans aparece indicado el 26 de junio de 1990, siendo que ese día ocurrido el altercado con carabineros, pero no su muerte, que fue al día siguiente. De igual modo, aparece el homicidio de Luis González Rivera, el 13 de febrero de 1990 , indicado como el primer asesinato político bajo los gobiernos de la Concertación de Partidos por la Democracia. Esto no es así ya que Patricio Aylwin comenzó su mandato presidencial el 11 de marzo de 1990, casi un mes después del hecho.

3 Véase Josefina Cuesta, "La historia del tiempo presente: estado de la cuestión", Studia Historica. Historia Contemporánea, 1, Salamanca, 1983, 227-241; Julio Aróstegui, "Historia y Tiempo Presente. Un nuevo horizonte de la historiografía contemporaneista", Cuadernos de Historia Contemporánea, 20, Madrid, 1998, 15-18; François Bédarida, "Definición, método y práctica de la Historia del Tiempo Presente", Cuadernos de Historia Contemporánea, 20, Madrid, 1998, 19-27; Jean-Pierre Rioux, "Historia del Tiempo Presente y demanda social", Cuadernos de Historia Contemporánea, 20, Madrid, 1998, 71-81; Hugo Fazio, "La historia del tiempo presente: una historia en construcción”, Historia Crítica, 17, Bogotá, julio-diciembre 1998, 47-57; Pierre Sauvage, "Una historia del tiempo presente", Historia Crítica, 17, Bogotá, julio-diciembre 1998, 59-70; Ángel Soto, "Historia del presente: estado de la cuestión y conceptualización”, Historia Actual Online, 3, Cádiz, invierno 2004, 101-116; Julio Aróstegui, "La historia del presente, ¿Una cuestión de método?", Carlos Navajas Zubeldia (ed.), Actas del IV Simposio de Historia Actual, Logroño, 17-19 de octubre de 2002, Gobierno de La Rioja, Instituto de Estudios Riojanos, Logroño, 2004, 41-75; Julio Aróstegui, La historia vivida. Sobre la historia del presente, Madrid, Alianza Editorial, 2004; Ángel Soto, El presente es historia, Santiago, Centro de Estudios Bicentenario, 2006; Peter Winn, "El pasado está presente. Historia y memoria en el Chile contemporáneo", Anne Pérotin-Dumon (dir.), Historizar el pasado vivo en América Latina, Santiago, Universidad Alberto Hurtado, Centro de Ética, 2007, 1-48; Danny Monsálvez, "La dictadura militar de Augusto Pinochet como Historia del Presente: historiografía, dictadura, 
inmediatamente la atención por su coetaneidad con la realidad de la actualidad del país. Asimismo, permite entender cómo, desde el gobierno de Patricio Aylwin, se consolidó una cultura política con fallas importantes para alcanzar la anhelada democracia plena.

Respecto al trabajo metodológico realizado, obviamente ésta responde al análisis histórico, aunque, al colindar con los esfuerzos de memoria y de la HTP, cuenta con sus particularidades. En primer lugar, se contactó a la familia de la víctima, concertando reuniones con ésta, particularmente con su viuda que le sobrevive; se intentó además contactar con los abogados involucrados y con el victimario, cuestiones que fueron imposibles en esta oportunidad, teniendo que extraer las opiniones de éstos desde otros lugares. En segundo lugar, se realizó un trabajo recopilando y analizando cada una de las publicaciones periódicas que salieron a la opinión publica del caso, las cuales abarcan más de cinco años. En tercer lugar, se relevó por primera vez el contenido del expediente del caso encontrado en el Centro de Documentación del Museo de la Memoria y los Derechos Humanos. Respecto a esto último, cabe destacar que, buena parte de la documentación usada para la elaboración de este artículo es de carácter completamente inédito.

\section{El primer asesinato político tras la vuelta a la democracia}

Osman Bernardo Yeomans Osorio era un joven de tan solo 23 años al fallecer. Pese a tan corta edad, Yeomans ya era esposo y padre para aquel entonces. De hecho, Sandra Jiménez Rodríguez, su viuda, es quien da cuenta de sus raíces: "Un hijo de familia sencilla, humilde. Militante comunista su padre, Osman; mujer de izquierda su madre, Hilda. Quinto hijo del matrimonio Yeomans Osorio, único hombre al lado de sus cuatro hermanas"4. Pese a las simpatías ideológicas de su familia, Yeomans fue criado en un ambiente católico, tradicional, en una casa "constituida" como señala Sandra. Fue esto, junto con el nacimiento del hijo de la pareja nueve meses antes, lo que probablemente impulsó a Yeomans a buscar casarse, cuestión que logró el 4 de febrero de 1988, inclusive con las aprensiones de Sandra, en aquel entonces una joven de 19 años, quien dice no arrepentirse en absoluto de la decisión ${ }^{5}$.

Su relación, como relata la propia Sandra, comienza con la política: "Con Osman militábamos juntos en La Jota, éramos militantes de Las Juventudes Comunistas de Chile en Lo Espejo. Su chapa, Marcelo"6. Si bien, para el día de su muerte, Yeomans se desempeñaba como obrero metalúrgico en la Metalúrgica Morgan y Fuenzalida S.A.7, lugar en el que había conseguido cierta estabilidad económica y notoriedad como dirigente sindical, él seguía militando, militancia que mantendría hasta el día de su muerte.

Hasta que llegó el día en que íbamos a hacer un rayado en homenaje al natalicio de Salvador Allende. Las paradojas de la vida. Osman Francisco nació el 25 de junio de 1987, tres años, día en que se nos convocó para el rayado, ese mismo día en la noche, a pegar papelografos, esa era la idea. Pero no preparamos papelografos. Bueno, pero había que hacer algo por Allende igual, así que quedamos con hacerlo al otro día, el día 26, esa era la orden que se dio en la reunión de base ${ }^{8}$.

transición, demanda social y crisis de representatividad”, Historia Actual Online, 30, Cádiz, invierno 2013, 175-191; Diego Díaz, "La Historia del Tiempo Presente. Breve revisión a la disciplina del estudio histórico de las dinámicas de la sociedad actual", Revista Abordajes, 1:2, La Rioja, segundo semestre 2013, 5-29; Henry Rousso, La última catástrofe. La historia, el presente, lo contemporáneo, Santiago, Editorial Universitaria, 2018.

${ }^{4}$ Entrevista con Sandra Jiménez Rodríguez, Santiago, 7 de mayo de 2018.

5 Idem.

${ }^{6}$ Idem.

7 "Investigan muerte de un militante de las JJ.CC.", La Tercera, Santiago, 28 de junio de 1990, 25.

${ }^{8}$ Entrevista con Sandra Jiménez Rodríguez, Santiago, 7 de mayo de 2018. 
Fue así cómo la noche del 26 de junio de 1990, Yeomans termina saliendo a las calles de Lo Espejo, junto con otros cuatro militantes, Cristian Becerra (25 años), Luis Corbalán (18 años), Marcos Suarez (28 años) y Omar Opazo (18 años), primo de Sandra ${ }^{9}$. Todo esto con el único fin de conmemorar el natalicio de Salvador Allende. Si bien, la documentación no es precisa respecto al lugar exacto donde se llevó a cabo el rayado ${ }^{10}$, no hay duda que éste tuvo lugar en algún punto entre la intersección de lo que hoy conocemos como la Avenida Lo Espejo y La Divisa, probablemente en esta última arteria vehicular. Fue en aquel lugar, cerca de la medianoche, donde un grupo de carabineros detuvieron a los muralistas.

Es en este punto que las versiones comienzan a volverse confusas y hasta contradictorias. Parte de ello responde, posiblemente, a que fue recién el 28 de junio cuando el hecho se hizo parte de la opinión publica gracias a la prensa escrita. "Según las versiones, sorpresivamente llegó al lugar un automóvil color azul metálico, del cual habrían descendido tres carabineros. Dos de los cinco muralistas intentaron huir y se sintió un disparo, a consecuencia del cual quedó tendido en el suelo Osmán Yeomán"11, señalaba La Tercera. Curioso es que, al día siguiente, el mismo periódico hable de "OTRAS VERSIONES", reparando en el indebido uso de "un vehículo particular para el patrullaje" o "el uso sin causa justificada del arma de servicio para detener a quien estaba cometiendo una falta menor". Más importante que todo esto, es que por primera vez se habla de "que los efectivos, tras darse cuenta de la gravedad de los hechos, trataron de cambiar el origen de los mismos e -incluso- llegaron a argumentar un accidente automovilístico, descubriendo el personal médico que el lesionado estaba herido de bala" 12 .

Otro medio de prensa escrita, Las Últimas Noticias, corrobora estos últimos dichos, también el 29 de junio, agregando que todo se desencadenó cuando "el rondín de la industria química «Lo Espejo» solicitó colaboración policial al suboficial de guardia del retén jurisdiccional del área, al denunciar posibles robos de cables del tendido electrónico del sector" ${ }^{\prime 3}$. Fue ante esto que los tres uniformados fueron enviados a patrullar, en un vehículo particular sin clara propiedad, aunque de marca aparentemente japonesa y con patente terminada en 22-6314, y junto al mismo denunciante, Fabián Alfonso Moreno Chávez"15. Es más, en las páginas de Las Últimas Noticias se aclara que fue "el comité central de las Juventudes Comunistas [quien] afirmó, a través de un comunicado, que Carabineros ingresó el propagandista herido en calidad de atropellado, encubriendo el baleo que había ocurrido", agregando en el mismo que "Esperamos que el gobierno responda, como nunca lo hizo la dictadura, haciendo justicia y tomando las medidas necesarias"16.

Los demás medios de prensa escrita, como La Segunda, La Época, La Nación y ElMercurio, solo se conformaron con replicar la noticia ya expuesta durante esos días, con mayor o menor extensión. Sin embargo, fue el 30 de junio cuando El Siglo, semanario oficial del Comité Central del Partido Comunista de Chile, se hizo con la noticia. "PINTAR POR ALLENDE AÚN ES UN DELITO", señaló en su titular. "Corría detrás nuestro y nos insultaba; lo único que yo hacía era mirar a Osmán, él me guiaba porque no conozco para nada el lugar. De pronto sentí el silbido de una bala y él cayó de una manera

\footnotetext{
9 "Expediente Caso Osman Yeomans", Santiago, Centro de Documentación del Museo de la Memoria y los Derechos Humanos, 9.

${ }^{10}$ En el "Expediente Caso Osman Yeomans", ubicado en el Centro de Documentación del Museo de la Memoria y los Derechos Humanos, además de diversa documentación legal, se encuentran las querellas emitidas por el caso, algunas en las cuales se señala que Yeomans y sus compañeros "se reúnen en las afueras de la industria ANASAC, más precisamente, en el pequeño callejón que separa esta de la textil "Lo Espejo" a fin de realizar un mural", mientras que en otras se menciona que esto ocurrió "en las inmediaciones de la planta de Lo Espejo de la industria Anasac, concretamente en los muros de la "Textil Lo Espejo" ubicada en la arteria llamada Camino Lo Espejo", correspondientes a las fojas 7 y 13.

11 "Investigan muerte de un militante de las JJ.CC.", La Tercera, Santiago, 28 de junio de 1990, 25.

12 "De baja 3 carabineros por baleo a muralista", La Tercera, Santiago, 29 de junio de 1990, 6.

13 "Dieron de baja a tres carabineros", Las Últimas Noticias, Santiago, 29 de junio de 1990, 17.

14 "Expediente Caso Osman Yeomans", Santiago, Centro de Documentación del Museo de la Memoria y los Derechos Humanos, 2.

15 Ibid., 48.

16 "Dieron de baja a tres carabineros", Las Últimas Noticias, Santiago, 29 de junio de 1990, 17.
} 
extraña, seco... Tengo su rostro grabado en mi mente; le grité y no respondió"17, relató en aquel entonces Omar Opazo. A sus familiares, corroboró el semanario, se les informó primeramente que el joven había sido atropellado por un camión, misma versión que entregaron los carabineros involucrados al dejar a Yeomans en el Hospital Barros Luco. Empero, las verdaderas suspicacias se levantan al señalar que dicha versión podría "tener un asidero real", ya que "La detección de un politraumatismo bien podría revelar que, luego de herido de bala, Osmán fue atropellado con la intención de ocultar la verdadera causa"18. De hecho, La Tercera había hecho la primera mención a esto, señalando que "Tras los hechos, es sabido, se sucedieron una serie de anomalías internas, entre quienes actuaron directamente en la detención de los brigadistas, los que estaban a cargo de los procedimientos policiales en la posta del Hospital Barros Luco, los encargados de la guardia de la unidad y los responsables del turno", quienes "indirectamente, engañada o con conocimiento, habrían tratado de cambiar o dar otro sentido a los hechos"19.

Si bien, el Certificado de Defunción, emitido el 28 de junio, es claro al señalar un "Traumatismo cráneo encefálico por bala" 20 , parece que el intento de los carabineros por hacer pasar el asesinato de Yeomans por un accidente automovilístico no fue solo un rumor sensacionalista. En la querella criminal llevada a cabo por la Corporación de Promoción y Defensa de los Derechos del Pueblo (CODEPU), institución que se hizo cargo del caso de Yeomans frente a la Justicia Militar, se solicita expresamente "Periciar las ropas del fallecido que en este momento acompañe, a fin de determinar si además de las lesiones del disparo mortal sufrió algún otro maltrato"21. Es más, en otro documento enviado por la CODEPU a la Justicia Militar, se dice que "a la familia y dirigentes del sindicato donde trabajaba se les informo que las lesiones habían sido producidas en un atropello, intentando encubrir con irregularidades administrativas el delito cometido"22.

Es la propia Sandra quien, reconstruyendo duros momentos del pasado, corrobora mucho de lo dicho por los medios de comunicación en aquellos días y enriquece lo expuesto otorgando la perspectiva de quien fue parte de los hechos. "Esa noche comenzó toda una búsqueda de Osman", señala, donde Danilo Rojas, compañero de militancia de la pareja, y Carlos Soto, dirigente público de Las Juventudes Comunistas de Chile en Lo Espejo, fueron los primeros en acompañarla. "Y nos encontramos con tres chicos más, que nos dijeron que no podíamos acercarnos, porque los pacos nos iban a llevar presos. También nos dijeron que el Osman y todos los demás salieron arrancando". Hasta ese momento, Sandra confiesa que solo temía por que su marido fuera detenido, golpeado y humillado, prácticas que a su parecer eran habituales. "Salimos todos en busca de Osman, que debía andar por ahí escondido. Llegamos al lugar del rayado y veo en la calle, al medio de la calle, una bufanda. La tomó y digo 'Esto es del Osman', estaba segura". Los tíos de Sandra, dirigentes comunistas, habían llegado semanas antes desde Moscú, trayendo consigo no solo al ya mencionado Omar Opazo, sino que también una bufanda de marca Siria como regalo para Yeomans. "Estaba completamente ensangrentada"23.

"A Carlos lo llama alguien de una empresa, a mí no me dice nada, y me dice 'Negra, vámonos al retén', ‘Está preso el Osman?’, 'Vamonos al retén'. Fuimos todos, ya éramos como seis”. Recuerda Sandra que fue Carlos Soto el primero en enfrentarse a los carabineros, al preguntar por Yeomans y recibir la respuesta de que éste había sido atropellado, Soto habría señalado “¿Desde cuándo acá que las balas atropellan?". Sandra confiesa que aún no se enteraba de lo sucedido. Pese a las negativas, el

\footnotetext{
17 Carolina Aranguiz, "La democracia cobra primera víctima”, El Siglo, Santiago, 30 de junio de 1990, 13.

18 Ibidem.

19 "Tres oficiales de baja por baleo a muralista", La Tercera, Santiago, 2 de julio de 1990, 4.

20 "Expediente Caso Osman Yeomans", Santiago, Centro de Documentación del Museo de la Memoria y los Derechos Humanos, 52.

21 Ibid., 10. Dicha petición se repite en otros documentos enviados por la CODEPU a la Justicia Militar, como en las f. 12 y 19.

22 Ibid., 14.

${ }^{23}$ Entrevista con Sandra Jiménez Rodríguez, Santiago, 7 de mayo de 2018.
} 
carabinero interpelado terminó señalando que Yeomans estaba en el Hospital Barros Luco. "Fue una larga noche. Esperamos en la salida de urgencias toda la noche, absolutamente toda la noche" 24 .

En paralelo a esto, los demás compañeros de Yeomans, tomados por carabineros en el lugar del rayado, salvo Omar Opazo, quien realmente había logrado huir, habían sido llevados a la comisaria de Lo Sierra $^{25}$. Sin embargo, el cómo llegaron ahí solo añade más extrañeza al caso. Es en un documento enviado por la CODEPU a Justicia Militar donde se señala que "Los detenidos fueron subidos a un vehículo de la locomoción colectiva que transitaba por el camino Lo Sierra y trasladados a la Tenencia de Lo Sierra, donde fueron puestos en libertad a las pocas horas"26. Además, en otro documento, se señala que "Los detenidos fueron puestos en libertad sin comunicarles la situación producida y sin que se les anotara en el registro correspondiente" 27 . Claramente, fueron muchas las irregularidades cometidas por los carabineros involucrados en el asesinato de Yeomans, más allá del propio crimen. Todo indica, además de cierta desprolijidad e improvisación, que los carabineros involucrados trataron simplemente de cubrir el hecho, cuestión en la que fallaron, pues Carabineros de Chile tuvo que asumir públicamente las responsabilidades y los cuestionamientos que se le hicieron por estas irregularidades ${ }^{28}$. La propia Sandra saca a colación la declaración de una joven que, si bien en aquel momento no prestó declaración por miedo, al parecer atestiguó cómo el carabinero responsable del disparo "se paró al lado de Osman, caminó de un lado para otro, se agarró la cabeza con las dos manos y corrió el cuerpo de Osman”"29.

Marcos Suarez, detenido junto a Cristian Becerra y Luis Corbalán, declaró al respecto que "En el retén estuvimos como hora y media, nos preguntaron qué estábamos haciendo, si éramos de la Jota y luego nos soltaron", sin embargo, y más allá de las versiones que hablan de ciertos maltratos por parte de carabineros durante la detención, éste señaló a continuación, "Yo escuche una llamada y el sargento parece que era sargento- dijo que si estaba muerto o se movía, si acaso lo habían atropellado, entonces nosotros salimos y fuimos a buscarlo a la casa a ver si había llegado, pero llego solamente el primo"30.

"A las seis de la mañana vuelvo a mi domicilio y está mi primo, Omar, con la cabeza agarrada a dos manos, quería estar solo. Y algo dice, 'Yo te voy a acompañar', pero yo tenía que pasar primero a la empresa del Osman, no quería que perdiera su pega". Sandra, pensando que realmente había sido atropellado, solo se preocupaba por mantener las cosas en calma para la vuelta de su marido. Nadie se había atrevido aún a decirle lo ocurrido. "Tipo diez de la mañana logró entrar al hospital para saber qué pasó con Osman, comienza a llegar prensa, se presenta alguien del CODEPU, Hiram Villagra, llega mi tía, militantes del partido, comienza a llegar mucha gente". Sandra comenzaba a sospechar, pero reconoce que el enceguecimiento no le permitió ver la realidad. "Entró a una sala donde venían dos personas hablando, tratando de descifrar el apellido. 'Es Yeomans', y me dicen '¿Usted lo conoce?', 'Sí, es mi marido’. [...] ‘¿Y qué le pasó?’, 'Lo atropellaron’. Y la auxiliar, paramédico, no sé lo que era, me dice ‘No,

\footnotetext{
${ }^{24}$ Idem.

25 "Investigan muerte de un militante de las JJ.CC.", La Tercera, Santiago, 28 de junio de 1990, 25.

26 "Expediente Caso Osman Yeomans", Santiago, Centro de Documentación del Museo de la Memoria y los Derechos Humanos, 8.

27 Ibid., 14.

28 Véase "Investigan muerte de un militante de las JJ.CC.", La Tercera, Santiago, 28 de junio de 1990, 25; "De baja 3 carabineros por baleo a muralista", La Tercera, Santiago, 29 de junio de 1990, 6; "Gobierno lamentó hechos", La Tercera, Santiago, 29 de junio de 1990, 6; "Esta tarde son funerales de brigadista de JJ.CC.", La Tercera, Santiago, 29 de junio de 1990, 6; "Fiscal reconstituyó baleo", La Tercera, Santiago, 29 de junio de 1990, 6; "Tres oficiales de baja por baleo a muralista", La Tercera, Santiago, 2 de julio de 1990, 4; "Oficiales de Carabineros no han sido dados de baja", La Tercera, Santiago, 3 de julio de 1990, 6; "Muere joven comunista", Análisis, Santiago, No 338, 2 al 8 de julio de 1990, 23; Carolina Aranguiz, "La democracia cobra primera víctima", El Siglo, Santiago, 30 de junio de 1990, 1 y 13-15; "Carabineros dio de baja a 3 policías por muerte de muralista del PC", La Segunda, Santiago, 28 de junio de 1990, 3; "Dieron de baja a tres carabineros", Las Últimas Noticias, Santiago, 29 de junio de 1990, 17; "Belisario Velasco asistió a funerales de joven comunista", Las Últimas Noticias, Santiago, 30 de junio de 1990, 15.

${ }^{29}$ Entrevista con Sandra Jiménez Rodríguez, Santiago, 7 de mayo de 2018.

30 "Expediente Caso Osman Yeomans", Santiago, Centro de Documentación del Museo de la Memoria y los Derechos Humanos, 59.
} 
a su marido le dispararon, miré, yo llevo la radiografía, la bala está alojada en su cráneo"'. Fue en ese momento que Sandra, aún reticente, se entera de lo que realmente ocurrió con su marido. De hecho, ella misma confiesa que el doctor Lopetegui, a cargo del equipo médico que trató de salvarle la vida a su marido, le indicó la gravedad del asunto, incitándola a contactar con un abogado 31 . "Le pido al doctor que me deje entrar y despedirme. Pasó el rato, no sé cuánto". Fueron alrededor de tres horas las que esperó para despedirse de su marido. "Estoy en la puerta de la sala donde lo había visto a través de un vidrio, me señalan que espere, y en ese momento entra mi tía y le pregunto si va a entrar conmigo, me pasa un vaso con agua y me dice que Osman fallece en el momento que yo entro al hospital. No me alcance a despedir del Osman"32.

Son muchas y de distinta índole las cuestiones en que se podría detener, pero no hay duda que el asesinato de Osman Yeomans no solo significó una mella irreparable entre sus seres queridos, sino que también, lamentablemente, pasó a constituir el listado de asesinados políticos tras la vuelta a la democracia.

\section{Las omisiones del gobierno de Patricio Aylwin.}

El 11 de marzo de 1990 se tiene por la fecha en que la democracia vuelve al país. Fue ese el día en que, tras casi 17 años de dictadura, Patricio Aylwin llega al Palacio de La Moneda. Más allá de los distintos obstáculos con que se enfrentó, es necesario tener en cuenta que el gobierno de Patricio Aylwin, sin importar los juicios de valor que se le puedan hacer, tenía la misión de traer al país la tan anhelada alegría de la cual hablaban las propagandas contrarias a la dictadura. Sin embargo, ésta parecía ser esquiva a tan solo 100 días de su mandato. El 21 de junio, en una conferencia de prensa frente a 50 periodistas nacionales y 41 extranjeros, Patricio Aylwin se refirió a los primeros días de su gobierno, "Sin jactancia de ninguna especie, por el contrario, con humildad, siento la satisfacción de que estamos partiendo bien. Creo que el país está aprendiendo a vivir en democracia. Hay en Chile amplia libertad"33. Similares comentarios, claramente optimistas, eran fáciles de encontrar en las bocas de otros personajes de la época. Todo ello hacía eco de lo que significó la vuelta a la democracia en Chile. Sin embargo, dichos balances eran, a lo menos, sesgados. "Las encuestas de opinión indican que sigue en aumento la popularidad del Presidente Aylwin, que ya llega a un 88 por ciento. Los chilenos de todos los niveles están satisfechos con su labor y manifiestan confianza en su moderación, su espíritu democrático y en su prudencia", es más, y es lo relevante para esta investigación, se puntualiza en que dichas virtudes "no excluye la firmeza de su carácter para rechazar los tironeos del extremismo ni la audacia para emprender caminos originales que lleven al fortalecimiento de la democracia"34.

Pese a lo anterior, durante los primeros 100 días del gobierno de Patricio Aylwin no solo se vivió alegría. Si bien, tímidamente se comenzaban a dar gestos en favor de una real consolidación de la democracia y la reconciliación con la historia reciente del país, particularmente con los mismos homenajes públicos hechos por el natalicio de Salvador Allende, en la Plaza de la Constitución en Santiago y el Cementerio Santa Inés en Viña del Mar ${ }^{35}$, los cuales estuvieron acompañados, además, por la entrega de los bienes de la familia Allende Bussi, en manos del Ministerio de Salud desde 1974, a Hortensia Bussi ${ }^{36}$, la alegría aun así no era una realidad para todos los chilenos. Como la propia Sandra declara, en relación al homicidio de Yeomans, "Días antes habían sido identificados los primeros cuerpos de detenidos

\footnotetext{
31 Entrevista con Sandra Jiménez Rodríguez, Santiago, 7 de mayo de 2018.

32 Idem.

33 Francisco Martorell, "Los cien días de Aylwin”, Análisis, Santiago, N 337, 25 de junio a 1 de julio de 1990, 9.

34 Luciano Vásquez Muruaga, “Los primeros cien días”, Las Últimas Noticias, Santiago, 28 de junio de 1990, 9.

35 "Ex ministros rindieron su homenaje a Allende", Las Últimas Noticias, Santiago, 28 de junio de 1990, 3.

36 "Entregan los bienes de familia Allende Bussi", La Tercera, Santiago, 27 de junio de 1990, 14.
} 
desaparecidos"37. De hecho, fue el 2 de junio de 1990 cuando se hallaron distintas fosas comunes clandestinas en Pisagua, con una veintena de cuerpos de detenidos desaparecidos. Esto potenció la labor de la Comisión Nacional del Verdad y Reconciliación, creada por el gobierno de Patricio Aylwin y encargada de esclarecer las violaciones a los derechos humanos cometidas durante la dictadura ${ }^{38}$, la cual había sido fuertemente cuestionada desde su inicio por la derecha política, dichos que acallaron luego del hallazgo ${ }^{39}$. Esta revelación, sin embargo, era solo una de las tantas que comenzaban a hacerse parte de la opinión pública. El caso de Carmen Gloria Quintana y Rodrigo Rojas de Negri, ambos quemados vivos por militares en plena dictadura, conllevando el fallecimiento de este último, se comenzaba a discutir judicialmente ${ }^{40}$. Asimismo, las atrocidades no solo parecían venir del pasado, sino que también se veían en el día a día. El Movimiento Juvenil Lautaro, grupo armado de extrema izquierda ${ }^{41}$, se enfrentaba a Carabineros de Chile habitualmente en distintas poblaciones, dejando heridos por ambos lados, como si de una guerra civil se tratara ${ }^{42}$. La violencia era, sin lugar a dudas, el mayor miedo de los chilenos de la época, cuestión que indicaban las propias encuestas ${ }^{43}$. Tanto en su pasado reciente como en su presente, los chilenos eran testigos de cómo se extendía la violencia inusitadamente en el país, indicador inequívoco para algunos de que el 11 de marzo de 1990, si bien significó la vuelta a la democracia, no necesariamente fue el arribo de la alegría.

En este sentido, durante el gobierno de Patricio Aylwin, más allá de los reales logros alcanzados, se puede evidenciar la permanencia de dos graves y discutibles aspectos de la cultura política que prevalecía por aquel entonces. Si bien, el término se ha vuelto polisémico y hasta ambiguo desde el auge contemporáneo que alcanzó gracias a Gabriel Almond y Sidney Verba ${ }^{44}$, mucho de lo expuesto sobre la cultura política por éstos aún sigue presente. De hecho, se puede apreciar que, según su esquematización, los ya mencionados dos aspectos problemáticos de la cultura política durante el gobierno de Patricio Aylwin responden al proceso político (input) y al proceso administrativo (output), es decir, la corriente de demandas que van desde la población civil al gobierno de turno y cómo éste aplica su principio de autoridad, en tanto gobierno, frente a distintas problemáticas ${ }^{45}$.

El primero de estos aspectos hace alusión a las demandas sostenidas por parte de la población civil en la búsqueda de verdad, justicia y reparación sobre las violaciones a los derechos humanos cometidas durante la dictadura. Si bien, ya se ha hablado un poco de ello, es interesante reparar en el hecho de que dicha búsqueda, que legalmente terminaba el 11 de marzo de 1990 gracias a la Ley $\mathrm{N}^{\circ}$ 19.123, promulgada el 31 de enero de 1992 por el Ministerio del Interior y que creaba la Corporación Nacional de Reparación y Reconciliación ${ }^{46}$, iba más allá. Por un lado, quienes sobrevivieron a las víctimas

\footnotetext{
${ }_{37}$ Entrevista con Sandra Jiménez Rodríguez, Santiago, 7 de mayo de 2018.

38 Elizabeth Lira y Brian Loveman, Politicas de reparación. Chile 1990-2004, Santiago, LOM Ediciones, 2005, 128-151.

39 Iban Badilla, "Comisión Rettig. Encontrarse con la verdad", Análisis, Santiago, № 337, 25 de junio a 1 de julio de 1990, 1011.

40 "Pendiente fallo sobre 'Caso Quemados", La Segunda, Santiago, 28 de junio de 1990, 4.

41 Véase Eyleen Faure, Los locos del poder: aproximación histórica a la experiencia del Movimiento Juvenil Lautaro (1982-1997), Santiago, Pukayana Editorial, 2006; Pablo Pozzi y Claudio Pérez (eds.), Historia oral e historia política. Izquierda y lucha armada en América Latina, 1960-1990, Santiago, LOM Ediciones, 2012; Nicolás Acevedo, MAPU-LAUTARO, Concepción, Ediciones Escaparate, 2014. Según éstos y otros autores, el Movimiento Juvenil Lautaro tuvo una estructura organizacional más cercana a la de una milicia, a la de un aparato militar clásico, más que a la de una guerrilla.

42 "Frente Lautaro atacó con fuego de metralletas un furgón de Carabineros: dos heridos", La Segunda, Santiago, 4 de julio de $1990,2$.

43 “¿Qué miedos tienen los chilenos?”, La Segunda, Santiago, 13 de marzo de 1992, 34-37.

44 Cecilia Schneider y Karen Avenburg, "Cultura política: un concepto atravesado por dos enfoques", Post Data, 20:1, Buenos Aires, junio de 2015, 109-110.

45 Gabriel Almond y Sidney Vera, La cultura cívica: Estudio sobre la participación política democrática en cinco naciones, Madrid, Euramérica, 1963, 19-60.

46 Pese al significativo avance que dicha acción legal significó, tanto ésta como sus posteriores modificaciones, comprendidas en la Ley $\mathrm{N}^{\circ} 19.980$ y la Ley $\mathrm{N}^{\circ} 20.405$, promulgadas el 29 de octubre de 2004 y el 24 de noviembre de 2009, respectivamente, se vieron limitadas en gran medida por el establecimiento del 11 de marzo de 1990 como fecha de vuelta a la democracia,
} 
o éstas mismas no se sintieron del todo satisfechas con las medidas tomadas. La Agrupación de Familiares de Detenidos Desaparecidos, por ejemplo, objetó la propuesta del gobierno de declarar la muerte presunta y expresó desconfianza respecto a la creación de una corporación de derecho público sin facultades para investigar el paradero de los detenidos desaparecidos. Denunció además el carácter injusto de una "pensión única" que no tomaba en cuenta el número de los integrantes de cada familia ${ }^{47}$. Por otro lado, la cifra de muertos a manos de funcionarios públicos ascendía a 96 entre 1990 y 1994, según cifras de la CODEPU. A Carabineros de Chile se le atribuían el 75\% de dichos fallecimientos, a Policía de Investigaciones de Chile el 11\%, a Gendarmería de Chile el 9\% y al Ejército de Chile el 5\%. Curiosamente, de los 96 fallecidos, solo 32 se habían visto envueltos en enfrentamiento o supuestos enfrentamientos ${ }^{48}$. Obviamente, estas y otras víctimas quedaron relegados de los beneficios que la Ley No 19.123 proponía, puesto que el 11 de marzo de 1990 se tenía como fecha límite para cualquier tipo de reparación. Como ya fue señalado, Yeomans solo fue el primero de un listado de asesinados políticos tras la vuelta a la democracia. Su caso, aunque particular, tristemente estuvo lejos de ser el único. Esto solo significó la permanencia de las demandas por verdad, justicia y reparación, pero ya no solo por aquellas víctimas del pasado, que comenzaban a surgir de su entierro, sino que también por aquellas que sufrían los embates de distintos funcionarios públicos, partes activas del gobierno de turno, sin mediar muchas veces en la racionalidad, como el propio Yeomans.

El segundo aspecto, vinculado con lo ya mencionado, tiene relación con la aparente conciencia de impunidad que existió dentro de ciertas instituciones públicas durante el gobierno de Patricio Aylwin. Según Manuel Antonio Garretón, este gobierno fue "una transición o democratización incompleta, que dejó un régimen democrático lleno de imperfecciones y enclaves autoritarios que limitan seriamente el ejercicio de la soberanía popular" 49 . Ello se tradujo en una conciencia de impunidad por parte de aquellos funcionarios públicos que recaían en los excesos cometidos durante los años recién pasados, en dictadura. De hecho, Luis Joinet, Relator Especial de la Organización de las Naciones Unidas para los Derechos Humanos, calificó al "sistema de impunidad" en Chile como la "injusticia organizada" 50 . Nuevamente, lo ocurrido con Yeomans es ejemplificador.

Víctor Manuel Sepúlveda Arriagada, Manuel Gilberto Arévalo Echeverría y Luis Alberto Contreras Riquelme son indicados en toda la prensa escrita como dados de baja de Carabineros de Chile por lo ocurrido con el joven muralista ${ }^{51}$, siendo solo el primero el responsable directo del disparo; e inclusive, en algunos periódicos se hizo mención al llamado a retiro de tres oficiales de esta institución, "el mayor de la $11^{a}$ Comisaría de la Población José María Caro; el capitán a cargo de los servicios de la misma unidad y el teniente que, el día de los hechos, estaba a cargo del turno", por su culpabilidad por el mando que tenían ${ }^{52}$. Dichas medidas se habrían tomado, posiblemente, por las ya mencionadas anomalías

significando una "tabla rasa" no solo para la opinión pública chilena, sino que también para la parte importante de la legalidad del país.

${ }^{47}$ Lira, op. cit., 134-135.

48 Corporación de Promoción y Defensa de los Derechos del Pueblo (CODEPU), Informe Derechos Humanos. 1990-1994, Santiago, abril de 1994, 20. Dichas cifran pueden ser contrastadas con las presentadas por Victoria Zapata, donde solo se habla de 27 asesinados políticos durante el gobierno de Patricio Aylwin, aunque existe la salvedad de que éstos son, exclusivamente, militantes de alguna institución política, a diferencia de las cifras de la CODEPU, que incluyen a cualquier persona fallecida a manos de funcionarios públicos. Véase Victoria Zapata, Cárcel de alta seguridad. Inbumanidad, represión y rebeldía, Santiago, Editorial Mare Nostrum, 2005, 146.

49 Manuel Antonio Garretón, "La cuestión del régimen de gobierno en el Chile de hoy", Jorge Lanzaro (comp.), Tipos de presidencialismo y coaliciones politicas en América Latina, Buenos Aires, CLACSO, 2001, 191.

50 Beatriz Brinkman, Itinerario de la impunidad. Chile 1973-1999. Un desafio a la dignidad, Santiago, CINTRAS, 1999, 16-17.

51 Véase "Dieron de baja a tres carabineros", Las Últimas Noticias, Santiago, 29 de junio de 1990, 17; "De baja 3 carabineros por baleo a muralista", La Tercera, Santiago, 29 de junio de 1990, 6; "Carabineros dio de baja a 3 policías por muerte de muralista del PC”, La Segunda, Santiago, 28 de junio de 1990, 3.

52 "Tres oficiales de baja por baleo a muralista", La Tercera, Santiago, 2 de julio de 1990, 4. 
que envolvieron el asesinato de Yeomans, las cuales rápidamente se hicieron de conocimiento de la opinión pública gracias a la prensa escrita.

Inclusive desde el propio gobierno de Patricio Aylwin se emitieron comentarios esclarecedores al respecto. Si bien, el Ministro Secretario General de Gobierno, Enrique Correa, "destacó la rapidez del alto mando de Carabineros en la determinación de las responsabilidades" 53 , fue Belisario Velasco, Ministro del Interior subrogante en aquel momento, el que declaró públicamente que "Un carabinero que hace uso indebido de su arma no involucra a una institución tan comprometida con los valores de la patria", recalcando en su declaración oficial que "un funcionario corrompido no compromete la pureza de los principios del partido en que milita, un soldado que ordena matar sin razón no hace a un Ejército de asesinos" 54 . El mismo Velasco asistiría a los funerales de Yeomans, realizados el 29 de junio en el Cementerio Metropolitano, donde un "millar de personas participaron" en su despedida, con absoluta normalidad ${ }^{55}$. En dicha ocasión, el personero "dijo que los policías involucrados en el hecho de sangre habían sido dados de baja y pasados para ser juzgados por los tribunales correspondientes" 56 .

Pese a esto, la conciencia de impunidad que existió dentro de ciertas instituciones públicas prevaleció gracias al propio actuar del gobierno de Patricio Aylwin. Si bien, los dichos emitidos tanto por Correa como Velasco pueden ser leídos como una condena clara a los involucrados en el asesinato de Yeomans, salvaguardando a la institución de Carabineros de Chile de paso, lo cierto es que dicha condena no llegó. Fue La Segunda el primer medio de prensa escrita que emitió esta noticia, el 2 de julio, replicando un comunicado entregado por la Jefatura de Zona Metropolitana de Carabineros de Chile, el cual señaló que ningún oficial había sido dado de baja por lo ocurrido y que los responsables directos serían sancionados al término del sumario interno que se llevaba a cabo ${ }^{57}$. El propio Hiram Villagra, uno de los primeros abogados de la CODEPU en tomar el caso, declaró que:

Enfrentado al tema de enjuiciar drásticamente a Carabineros y dar una señal fuerte de no tolerancia de esos temas, la democracia naciente no da el ancho y prefiere, por conveniencias políticas, activar mecanismos de impunidad. No hay una señal fuerte hacia Carabineros, en orden a sancionarlo drásticamente, al contrario, el carabinero que dispara contra Osman, permanece en servicio activo bajo el pretexto que mientras no sea condenado, no va a ser separado del servicio y es trasladado de unidad, primero fuera de Santiago y después regresa ${ }^{58}$.

De este modo, tras el asesinato de Yeomans, Carabineros de Chile recibe una clara señal de permisibilidad frente a eventuales excesos que pudiesen cometer. Si bien, es cierto que durante el gobierno de Patricio Aylwin no existía una orden clara de asesinar, como sí se podría acusar a la dictadura en algunos casos, este gesto de omisión les permite entender a ciertos funcionarios que no serían penalizados 59 . En la práctica, se favoreció "un accionar policial sin sujeción a las normas de un debido

53 "Dieron de baja a tres carabineros", Las Últimas Noticias, Santiago, 29 de junio de 1990, 17.

54 "Gobierno lamentó hechos", La Tercera, Santiago, 29 de junio de 1990, 6.

55 "Emotivos funerales del muralista de las JJ.CC.", La Tercera, Santiago, 30 de junio de 1990, 6. Además, en la portada de dicha edición, se puede atestiguar la masividad del funeral, siendo una de las primeras grandes manifestaciones de la población civil en las calles tras la vuelta a la democracia (p. 1).

56 "Belisario Velasco asistió a funerales de joven comunista", Las Últimas Noticias, Santiago, 30 de junio de 1990, 15.

57 "Carabineros: No han sido dados de baja 3 oficiales", La Segunda, Santiago, 2 de julio de 1990, 18. Dicha noticia sería replicada al día siguiente por otros medios. Véase "Oficiales de Carabineros no han sido dados de baja”, La Tercera, Santiago, 3 de julio de 1990,6 .

58 Entrevista con Hiram Villagra, Santiago, mayo de 2010. Dicha entrevista fue extraída de Susana Celis, Rebeldía y utopía, castigo y represión. Politicas Represivas en el Primer Gobierno de la Concertación, Profesor Guía: Hugo Godoy León. Reportaje para optar al Título de Periodista. Santiago, Facultad de Humanidades, Escuela de Periodismo, Universidad de Santiago de Chile, 2010, 175.

59 Susana Celis, Rebeldía y utopía, castigo y represión. Políticas Represivas en el Primer Gobierno de la Concertación, Profesor Guía: Hugo Godoy León. Reportaje para optar al Título de Periodista. Santiago, Facultad de Humanidades, Escuela de Periodismo, Universidad de Santiago de Chile, 2010, 175. 
respeto a los derechos humanos", además de establecer "un procedimiento penal que no da garantías de imparcialidad, con lo cual se asegura un alto grado de impunidad para delitos en los que se ven involucrados agentes del Estado"60. El propio Villagra profundizó en aquello:

Carabineros entendió claro el mensaje, no propiciamos que ustedes disparen, pero no los vamos a castigar si lo hacen y ese es el carácter que sea tan seria la muerte de Osman Yeomans, con todo lo dolorosa que es. La muerte es un abuso policial no asistente, los mecanismos de impunidad para impedir que esto tuviera el efecto político que debió haber tenido, sí habla de una política de Estado de impunidad, de tolerancia, de convivencia con la represión abierta que va a permitir que se rearme por ejemplo la violencia de Carabineros y empiecen a reaparecer hechos de violencia ya no como política de Estado, pero si como actos de fuerza que gozan de una no tolerancia, pero la ausencia de medidas drásticas de control y represión a la propia violencia represiva. [...] El caso de Osman más que expresión, es una causa de procesos posteriores, al hablar abiertamente de que la impunidad se mantiene no sólo a los crímenes del pasado, sino que, a los hechos del futuro, se creó la condición que permitió nuevos fenómenos. Fue la señal que la democracia naciente no quería o no podía, y esa es la duda, castigarlos como correspondía ${ }^{61}$.

La propia Sandra se refiere al respecto, no solo sobre la conciencia de impunidad que existía dentro de algunas instituciones, amparada por el gobierno de Patricio Aylwin, sino también por las actitudes arraigadas dentro de éstas. "En esos años, donde los cambios no se generaban automáticamente, era obvio que estaba todavía la violencia arraigada en la Fuerza, cosa que todavía hoy está instalada" 62.

"Los titulares eran claros: tres carabineros dados de baja. Nunca fueron dados de baja", señala Sandra. Es más, ella confiesa haber estado al pendiente de Sepúlveda, el carabinero que perpetró el tiro e hirió de muerte a su marido, asegurando que éste fue movido por Carabineros de Chile, para resguardar su persona, estando después en radiopatrullas y luego en la Población Santa Adriana, en Lo Espejo, siguiendo su carrera unos 8 años más y saliendo de la institución impunemente ${ }^{63}$. Dichas afirmaciones son corroboradas por la documentación existente, donde, en una carta de 7 de julio de 1993, entre Concejal de la Municipalidad de Lo Espejo, Verónica Canales Pizarro, y el Jefe de Gabinete Subrogante de Carabineros de Chile, Hugo Aguayo Cabezas, este último señala que "la Institución dispuso la instrucción de un Sumario Administrativo para establecer la forma y circunstancias en que ocurrieron los hechos, aplicándose a su término las medidas administrativas pertinentes, continuando el funcionario en las filas de Carabineros", gracias a que en dichos peritajes se estableció que "en el uso del arma de fuego por parte de éste, no existió dolo" 64 . Dicha información se replica en otra carta, esta vez entre la CODEPU y el ya mencionado Belisario Velasco, con fecha del 10 de septiembre de $1993^{65}$.

Pese a que la pena establecida en el Artículo 330 del Código de Justicia Militar señala el presidio mayor en sus grados mínimo a medio por causar la muerte, Víctor Sepúlveda parece no haber estado muy alejado de Carabineros de Chile. Fue el 4 de agosto de 1994 cuando se hizo pública la primera condena contra Sepúlveda. Fue el juez militar de Santiago, brigadier general Hernán Ramírez Rurange, quien lo

\footnotetext{
${ }^{60}$ Pedro Rosas, Rebeldía, subversión y prisión politica. Crimen y castigo en la transición cbilena 1990-2004, Santiago, Editorial Septiembre Negro, 2010, 204.

${ }^{61}$ Entrevista con Hiram Villagra, Santiago, mayo de 2010. Dicha entrevista fue extraída de Susana Celis, Rebeldía y utopía, castigo y represión. Politicas Represivas en el Primer Gobierno de la Concertación, Profesor Guía: Hugo Godoy León. Reportaje para optar al Título de Periodista. Santiago, Facultad de Humanidades, Escuela de Periodismo, Universidad de Santiago de Chile, 2010, $176-177$.

62 Entrevista con Sandra Jiménez Rodríguez, Santiago, 7 de mayo de 2018.

${ }^{63}$ Idem.

64 "Expediente Caso Osman Yeomans", Santiago, Centro de Documentación del Museo de la Memoria y los Derechos Humanos, 55.

${ }^{6}$ Ibid., 54.
} 
condenó a dos años de presidio como autor de violencia innecesaria con causa de muerte. Sin embargo, en el fallo, "el magistrado castrense remitió la pena al policía a firmar mensualmente, durante el tiempo de la condena, en la respectiva Fiscalía Militar" 66 . El caso siguió y fue recién el año siguiente, el 10 de noviembre de 1995, cuando se conoce el destino último de Sepúlveda. Con Adil Brkovic como representante del CODEPU en esta ocasión, Sepúlveda "fue condenado a la pena de tres años y un día de presidio menor en su grado máximo con remisión o cumplimiento alternativo de la condena, a través de la libertad vigilada". Más allá de la distancia entre dicha condena y el propio Código de Justicia Militar, Fue Brkovic quien indicó que, "el carabinero estuvo privado de libertad durante 200 días en la tenencia de Lo Espejo", días que serían finalmente rebajados de su condena ${ }^{67}$. Además, señaló que Sepúlveda, si bien había sido suspendido durante las primeras investigaciones hechas, prontamente había sido reintegrado a sus funciones, las cuales, por lo demás, no podía ejercer, ya que la pena accesoria de su condena lo inhabilitaban para cualquier cargo público mientras ésta durara ${ }^{68}$, cuestión que al parecer nunca se tomó en cuenta por Carabineros de Chile.

Lo ocurrido a Yeomans, nueva y tristemente, es solo uno de los tantos casos en que la conciencia de impunidad de ciertas instituciones públicas se ve respaldada por el gobierno de turno ${ }^{69}$. Si bien, el asesinato de Yeomans termina por instaurar jurisprudencia, volviéndose la condena más alta dada hasta la fecha a un uniformado, dicha condena, como señalan los implicados y muestra la documentación, jamás fue efectiva. Teniendo en cuenta esto, se puede suponer que el destino de los demás casos de asesinados a manos de funcionarios públicos durante el gobierno de Patricio Aylwin no debió ser muy distinto. Es más, Elizabeth Lira y Brian Loveman han demostrado ampliamente que, durante la transición democrática, se desplegó un actuar gubernamental basado en la impunidad, olvido y reconciliación, el cual se hizo extensible a los siguientes gobiernos democráticos hasta el día de hoy, a través de diversas estrategias políticas y jurídicas que han primado la estabilidad social y la continuidad institucional ${ }^{70}$. Aparentemente, el gobierno de Patricio Aylwin prefirió la convivencia a una verdadera reconciliación ${ }^{71}$.

Respecto a esto último, cabe destacar que no solo el gobierno de Patricio Aylwin no se comportó a la altura. Misma acusación se puede hacer sobre el Partido Comunista de Chile, el cual, frente al caso de Yeomans como de otros de sus militantes, se mostró a lo menos ecléctico. Si bien, se anunció que "El Comité Central de PC que a primera hora de hoy será presentada una querella por homicidio ante los tribunales contra quienes resulten culpables de su muerte y a las 13:30 los militantes juveniles de la

\footnotetext{
66 "Dos años a carabinero que mató de balazo a joven muralista en Lo Sierra", La Cuarta, Santiago, 4 de agosto de 1994, 4.

67 “Tres años para carabinero que mató a muralista en Lo Espejo", La Cuarta, Santiago, 10 de noviembre de 1995, 7.

${ }^{68} \mathrm{Idem}$.

${ }^{69}$ Véase Pedro Rosas, Rebeldía, subversión y prisión política. Crimen y castigo en la transición cbilena 1990-2004, Santiago, Editorial Septiembre Negro, 2010, 132. Se mencionan los icónicos casos de Aldo Norambuena Soto, militante del Movimiento Juvenil Lautaro que murió el 9 de agosto de 1990, a los 26 años, por un disparo de subametralladora en su cabeza, en medio de un enfrentamiento con Carabineros de Chile; Julio Eyzaguirre Reyes, militante del Movimiento Juvenil Lautaro que murió el 22 de agosto de 1990, a los 18 años, a raíz de un disparo realizado por un carabinero de civil; Marco Ariel Antonioletti, militante del Movimiento Juvenil Lautaro que murió el 15 de noviembre de 1990, a los 21 años, por un disparo directo en la frente, acción que se ha señalado como un tiro de "venganza" por parte de Policía de Investigaciones de Chile y que quedó impune; Luis González Rivera, militante del Frente Patriótico Manuel Rodríguez que murió el 13 de diciembre de 1990, a los 21 años, enfrentándose al GOPE. Cabe destacar que los ejemplos dados, a diferencia de los relevados por Zapata y la CODEPU, con 96 y 27 asesinados respectivamente, corresponden a las consecuencias de enfrentamientos, donde "la acción represiva respondió a la situación primando un uso proporcional de la fuerza en su defensa o en la contención de un ilícito o, por el contrario, si prevalecieron otros criterios de origen diverso, destinados a obtener como resultado la muerte o condiciones de muerte para los militantes" (132).

70 Véase Elizabeth Lira y Brian Loveman, Las ardientes cenizas del olvido: Via chilena de Reconciliación Politica 1932-1994, Santiago, LOM Ediciones, 2000; Elizabeth Lira y Brian Loveman, El espejismo de la reconciliación politica. Chile 1990-2002, Santiago, LOM Ediciones, 2002; Elizabeth Lira y Brian Loveman, Politicas de reparación. Chile 1990-2004, Santiago, LOM Ediciones, 2005. De hecho, en cada uno de estos libros, los autores plantean la existencia de una "Vía Chilena de Reconciliación", entre 1814 y 1994 , la cual favoreció la conciencia de impunidad entre algunos de sus funcionarios públicos.

${ }^{71}$ Lira, op. cit., 2002, p. 331.
} 
colectiva realizarán una protesta en la Plaza de Armas"72, dichos gestos parecen haber sido los únicos. Mismo actuar tuvo el Partido Comunista de Chile frente a otras violaciones a los derechos humanos de sus militantes durante estos años, no muy distinto al del gobierno de Patricio Aylwin. Aunque existió una condena pública, no se insistió en ello, dejándolo desaparecer rápidamente, así como toda noticia que llega a la opinión pública. En el caso del Partido Comunista de Chile, ello posiblemente respondió a sus afanes por colarse dentro de la Concertación de Partidos por la Democracia, coalición que sostuvo a Aylwin y sus sucesores en el gobierno.

Finalmente, se aprecia de este modo cómo ciertos aspectos de la cultura política, tanto de parte importante de la población civil que buscaba ciertas reivindicaciones, como de un gobierno que no puede o no quiere alterar a los miembros de su brazo armado, persisten gracias al gobierno de Patricio Aylwin, el cual pareciera haber preferido la omisión en ciertos casos, poniendo en duda la alegría que se prometía inicialmente. Si bien, no se puede hablar de una "corrupción estructural" en el sentido que Irma Sandoval propone, sí se aprecia "un diferencial de poder estructural en la que predominan el abuso, la impunidad" 73. Ello basta para suponer la poca importancia que este gobierno y sus sucesores dieron a aquellos estos casos. Asimismo, llama la atención la poca empatía con las víctimas. No puede olvidarse que los juicios, afrontados en medio de un clima de amenazas y/o de temor a las represalias, son experimentados como una situación de estrés traumático, que además aumenta el malestar y acrecentar la desconfianza en un Estado que no protege ni vela por el bienestar de sus ciudadanos ${ }^{74}$. De este modo, parece claro que el gobierno de Patricio Aylwin estaba dispuesto a pasar por alto muchas cosas antes de poner en riesgo la democracia que tanto había costado recuperar. Sin embargo, también parece claro que nadie se paró a pensar en cómo ello afectaría a esta democracia. Falta de pensamiento que lamentablemente es posible visibilizar en distintos casos a lo largo de los gobiernos que le siguieron.

\section{Allende, una bala y un final}

“A LOS 17 AÑOS DE SU MUERTE, SALUDAMOS EL NATALICIO DE SALVADOR ALLENDE JJ.CC.” 75 , este era el mensaje que el 26 de junio rayaban en un muro Yeomans y sus compañeros. Si bien, había quienes se negaban a cualquier tipo de rehabilitación de la figura de Salvador Allende en la escena pública, como el vicepresidente de Renovación Nacional, Miguel Otero, quien consideraba que esto podía "tener un serio riesgo político" "76, lo cierto es que durante el gobierno de Patricio Aylwin la figura de Allende fue ganando lugar en la escena pública, llegando incluso a aprobarse que se erigieran tres monumentos públicos del mandatario en distintas ciudades del país -Santiago, Valparaíso y Punta Arenas-, gracias a la Ley $\mathrm{N}^{\circ}$ 19.311, promulgada el 24 de junio de 1994 por el Ministerio del Interior ${ }^{77}$. En medio de dichos contrastes se ubicaron Yeomans y sus compañeros.

Lo hecho aquella noche puede entenderse no solo como el rayado por la conmemoración de Salvador Allende, sino que también puede ser visto como un símbolo, parte de un ritual político mayor. Todas las manifestaciones exteriores del poder buscan producir estas impresiones que se nutren de la

\footnotetext{
72 “Muralista de Juventudes Comunistas murió baleado", Las Últimas Noticias, Santiago, 28 de junio de 1990, 18.

${ }^{73}$ Irma Sandoval, "Enfoque de la corrupción estructural: poder, impunidad y voz ciudadana", Revista Mexicana de Sociología, 78:1, Ciudad de México, enero-marzo 2016, 123. Según la autora, la "corrupción estatal” es "una forma específica de dominación social sustentada en un diferencial de poder estructural en la que predominan el abuso, la impunidad y la apropiación indebida de los recursos de la ciudadanía", cuestión que se acerca más a la experiencia en dictadura que tras la vuelta de la democracia.

${ }^{74}$ Luis Cabrera, "Efectos de la impunidad en el sentido de justicia", Psicología Política, 23, Valencia, 2001, 55.

75 "Dieron de baja a tres carabineros", Las Últimas Noticias, Santiago, 29 de junio de 1990, 17; "La sangre regó la noche", La Semana Grafica (Suplemento de Las Últimas Noticias), Santiago, 1 de julio de 1990, 5.

76 “Actitud de Socialistas es peligrosa", Las Últimas Noticias, Santiago, 27 de junio de 1990, 3.

77 Antes de la promulgación y publicación de dicha ley, tuvo lugar la discusión en el Senado por ésta, el martes 14 de junio de 1994, instancia en la cual los comentarios aireados e inflamados de emociones no se hicieron esperar, tanto de políticos de izquierda, centro y derecha.
} 
historia, particularmente los rituales políticos. Éstos, han jugado un papel fundamental en la construcción de la legitimación del poder y la expansión de su hegemonía ${ }^{78}$, convirtiéndose en espacios donde solo los adictos, los militantes del partido en el poder y/o una facción del sector social dominante suelen participar $^{79}$. Ello no excluía a Yeomans y sus compañeros aquel 26 de junio de 1990.

De este modo, y como propone Sean Wilentz, el poder de los rituales políticos se relaciona con su capacidad para funcionar como mecanismos que generan una imagen de unidad y consenso alrededor de los más diferentes regímenes políticos, los cuales han reconocido su utilidad y se han aprovechado de ésta por siglos ${ }^{80}$. Los rituales políticos cumplirían así una particular doble función. Por un lado, crean una unidad simbólica entre los participantes que se reconocen a sí mismos como miembros de una comunidad política dada. Por otro lado, y en especial en regímenes de tipo autoritario, los rituales cumplen también una función de exclusión, privando de legitimidad como contendientes políticos a quienes no participan de los mismos. Entones, aquellos que no se asocian a la celebración son definidos como la otredad: antipatrióticos, antipueblo y/o enemigos públicos ${ }^{81}$. Los rituales políticos tienen además la función de reforzar y recrear simbólicamente ciertas fuentes de poder, dotando de legitimidad a un régimen político dado $^{82}$.

Además de esto, no se puede perder de vista que el ritual político genera un nexo, una especie de pacto tácito que conecta al individuo con valores colectivos, imprimiéndolos a fuego en los participantes más entregados al ritual ${ }^{83}$. El ritual político, por lo demás, se presenta como dispositivo de continuidad para el mismo poder, donde los artífices y/o cabecillas buscan legitimarse a sí mismos y a su proyecto político a través del propio ritual, generalmente retórico y escenificado, marcando una clara continuidad entre el presente y el pasado ${ }^{84}$. Queda así vislumbrada la relación activa y presente entre los rituales políticos y la historia. Las operaciones que el ritual ejercería sobre la historia modelarían la memoria colectiva, en un proceso que, no obstante, a la adhesión que el régimen político pueda tener, siempre se encuentra abierto y sujeto a interpretaciones, en el que concurren apropiaciones diferenciales de los significados del pasado.

El rayado hecho por Yeomans y sus compañeros aquella noche, debe ser entendido como un símbolo, parte de un ritual político mayor del cual ellos, en tanto militantes de las Juventudes Comunistas de Chile, así como otros miembros de la izquierda política chilena y simpatizantes de ésta o de la figura de Allende, eran parte. Éstos veían en el gobierno de Salvador Allende sueños de los cuales la dictadura los había despojado, y por fin ahora podían reivindicar esto en las calles, en la escena pública. Sin embargo,

\footnotetext{
78 Véase Juan Carlos Garavaglia, Construir el estado e inventar la nación. El Río de la Plata, siglos XVIII-XIX, Buenos Aires, Prometeo Libros, 2007, 57-88; José Carlos Chiaramonte, "Formas de identidad en el Río de la Plata luego de 1810", Boletín del Instituto de Historia Argentina y Americana "Dr. Emilio Ravignani", 3ra Serie, 1, Buenos Aires, 1er semestre de 1989; Robert H. Duncan, "Embracing a Suitable Past: Independence Celebrations under Mexico’s Second Empire, 1864-1866", Journal of Latin American Studies, Cambrigde, 30, mayo de 1998; Gyu P.C. Thomson, "Bulwarks of Patriotic Liberalism: The National Guard, Philharmonic Corps and Patriotic Juntas in Mexico, 1847-88", Journal of Latin American Studies, Cambridge, 22:1-2, febrero de 1990; Frances Kinloch, Politica y cultura en la transición al Estado- Nación, Nicaragua (1838-1858). Tesis de Maestría Académica en Historia. Costa Rica, Universidad de Costa Rica, 1999; Frances Kinloch, "Fiestas patrias: tradición y realidad (Nicaragua, 1858)", Margarita Vannini y Frances Kinloch (eds.), Politica, cultura y sociedad en Centroamérica. Siglos XVIII-XX, Managua, Instituto de Historia de Nicaragua y Centroamérica, Universidad Centroamericana, 1998; Patricia Fumero, "De la iniciativa individual a la cultura oficial. El caso del General José Dolores Estrada. Nicaragua, década de 1870", Frances Kinloch (ed.), Nicaragua en busca de su identidad, Managua, Instituto de Historia de Nicaragua y Centroamérica, Universidad Centroamericana, 1995.

79 Antonio Bonet Correa, Fiesta, poder y arquitectura. Aproximaciones al barroco español, Madrid, Ediciones Akal, $1990,30$.

80 Véase Sean Wilentz (ed.), Rites of Power: Symbolism, Ritual, and Politics since the Middle Ages, Pittsburgh, University of Pennsylvania Press, 1985.

81 Mona Ozouf, Festivals and the French Revolution, traducción de Alan Sheridan, Massachusetts, Harvard University Press, 1991, 12.

82 Claude Rivière, Les Liturgies politiques, París, Presses Universitaires de France, 1988, 176.

83 Pablo Ortemberg, "Sentidos e historia de las fiestas patrias: una introducción”, Pablo Ortemberg (dir.), El origen de las fiestas patrias. Hispanoamérica en la era de las independencias, Rosario, Prohistoria Ediciones, 2013, 20.

${ }^{84}$ Idem.
} 
y cabe destacar que, al menos en dicho rayado, no se puede detectar la presencia de un lenguaje belicoso, propio de las militancias políticas más acérrimas. Lo escrito esa noche solo buscaba traer nuevamente a Allende al presente, mitificándolo tal vez, pero sin ánimos de levantar mayores odiosidades entre quienes lo atestiguaran. Sin embargo, en esto último habrían fallado.

Más que anecdótico, es sintomático que el primer asesinato político ocurrido tras la vuelta a la democracia tenga como victimario a un carabinero uniformado, como víctima a un joven comunista y por telón de fondo a Allende. Dicha escena no solo reproduce las tensiones del pasado, como la polarización previa al golpe de Estado o los abusos cometidos en dictadura, sino que muestra su vigencia en el presente, en aquella noche. Más allá de lo accidental que allá podido resultar el asesinato de Yeomans, ya que al parecer no hubo premeditación al respecto por parte de Sepúlveda, lo cierto es que esta escena se repitió una y otra vez durante el gobierno de Patricio Aylwin, así como en el de sus sucesores, perpetuando aquellas tensiones.

\section{Palabras finales}

Las irregularidades cometidas esa noche y en todo el caso tras el asesinato de Yeomans ya han sido expuestas en buena medida, sin embargo, queda a entender que el hecho mismo, en toda su complejidad, solo refuerza la idea de Yeomans como el primer asesinato político ocurrido en la vuelta a la democracia. No es solo el hecho de que haya sido un carabinero con su arma de servicio el que le diera muerte; no es solo que Carabineros de Chile, como institución, lo protegieran; no es solo que el gobierno de Patricio Aylwin hiciera la vista gorda ante este caso y otros; no es solo que Yeomans haya sido militante de las Juventudes Comunistas de Chile; no es solo que todo ocurriera por un rayado por el natalicio de Salvador Allende. Es todo ello y más.

Si bien, la definición no es propia, puesto que ya El Siglo lo nombró en su momento como la primera víctima de la democracia ${ }^{85}$, cuestión que la CODEPU solo vino a confirmar con posterioridad ${ }^{86}$, reivindicar a Osman Bernardo Yeomans Osorio como el primer asesinado político tras la vuelta a la democracia en el país, parece necesario. No solo por el olvido que ha rodeado a su figura, tanto por parte del Estado como inclusive por quienes compartieron militancia con él, quienes solo últimamente y de manera esporádica han recordado su figura, sino porque marcó jurisprudencia para todos los casos que vendrían tras él y porque es un caso ejemplar de cómo el gobierno de Patricio Aylwin manejó situaciones tan complejas en medio de la transición, optando por la omisión. Asimismo, lo ocurrido a Yeomans es esclarecedor. Contrario a lo que se podría pensar del sentir de los chilenos tras la vuelta a la democracia, en dichos años el miedo a la violencia parecía común a todos y de aquello se daba cuenta. Con la presencia de Augusto Pinochet aún como Comandante en Jefe del Ejército de Chile, teniendo a su orden buena parte del brazo armado del país, era realmente difícil la posición del gobierno de Patricio Aylwin, teniendo que actuar de manera más que delicada para asegurar la transición, "En la medida de lo posible", como aquella frase él mismo señaló y lo inmortalizó. Sin embargo, y pese a esta precaución, esto no quita las culpas y no hace menos ciertos que el gobierno de Patricio Aylwin pudo haber sido más firme respecto a los abusos cometidos por sus funcionarios públicos, particularmente en casos tan alarmantes como el de Yeomans. Lamentablemente, parece que estas omisiones se perpetuaron, no solo al no encontrar justicia, sino que también al replicarse frente a casos de similares características que enfrentaron los gobiernos venideros.

De igual forma, cabe reparar en el actuar no solo del gobierno y sus funcionarios públicos, sino también en el que tuvo y ha tenido el Partido Comunista de Chile. Si bien, la propia Sandra señala que en

85 Carolina Aranguiz, "La democracia cobra primera víctima”, El Siglo, Santiago, 30 de junio de 1990, 13.

86 Corporación de Promoción y Defensa de los Derechos del Pueblo (CODEPU), Informe Derechos Humanos. 1990-1994, Santiago, abril de 1994, 30. 
los últimos años ha sabido de ciertos reconocimientos a Yeomans, como romerías y nombramientos ${ }^{87}$, no es menos cierto que su figura sigue prácticamente en el anonimato. Es más, su actuar frente a este y otros casos fue francamente cuestionable, pasando por alto en bienestar de sus militantes con tal de conseguir la gracia y participación en la Concertación de Partidos por la Democracia, coalición que sostuvo a buena parte de los gobiernos venideros tras 1990. Cabe preguntarse si, ya que no existió un apropiado comportamiento en su momento por su parte, ¿Le corresponde realmente a éste entonces hacer uso del primer asesinato político tras la vuelta a la democracia? Esta es una pregunta que se mantendrá abierta hasta el momento en que Yeomans u otra víctima hasta ahora anónima, se vuelvan parte de la ritualidad política del Partido Comunista de Chile ${ }^{88}$.

Finalmente, lo ocurrido con Yeomans es digno de recordar no solo por el hecho de que éste dejo tras de sí a una mujer, un hijo, padres y amigos, así como toda una vida por delante, todo por lo que aparentemente fue una mala acción, ni si quiera premeditada, de un carabinero que no cumplió la condena que debía pagar. Lo ocurrido con Yeomans es reflejo y caso ejemplificador de la HTP, particularmente de aquella realidad que se vivió durante la transición, la cual estuvo lejos de ser solo esa alegría que tanto se prometió antes de comenzar. Tristemente, las demandas por verdad, justicia y reparación por parte de la población civil, así como el actuar excesivo y la conciencia de impunidad sobre éste por parte de algunos funcionarios públicos, seguirían presente en la cultura política de los gobiernos posteriores al de Patricio Aylwin. Este último solo fue el primero en permitir este actuar, entendido en un contexto de transición democrática con características sumamente particulares, cuestión que, sin embargo, ha recibido poco cuestionamiento por parte de sus sucesores, quienes no ya habían superado buena parte de dichas características. Se podría hablar así una complicidad por comodidad, cuestión a definir en futuras investigaciones.

\section{Bibliografía}

\section{Libros:}

Acevedo, Nicolás, MAPU-LAUTARO, Concepción, Ediciones Escaparate, 2014.

Aróstegui, Julio, La historia vivida. Sobre la historia del presente, Madrid, Alianza Editorial, 2004.

Almond. Gabriel y Vera, Sidney, La cultura cívica: Estudio sobre la participación política democrática en cinco naciones, Madrid, Euramérica, 1963.

Brinkman, Beatriz, Itinerario de la impunidad. Chile 1973-1999. Un desafío a la dignidad, Santiago, CINTRAS, 1999.

Boeninger, Edgardo, Democracia en Chile. Lecciones para la gobernabilidad, Santiago, Editorial Andrés Bello, 1997.

\footnotetext{
87 Entrevista con Sandra Jiménez Rodríguez, Santiago, 7 de mayo de 2018.

88 Ángel del Río Sánchez y Félix Talego Vázquez, "Impugnando la impunidad. Las víctimas del franquismo frente al Estado", Periferias, fronteras y diálogos. Actas del XIII Congreso de Antropología de la Federación de Asociaciones de Antropología del Estado Español, Tarragona, Universitat Rovira i Virgili, 2014, 3170-3172. Cabe destacar que, en el caso de las víctimas de derechos humanos por el franquismo, la ritualidad política parece surgir desde ellos mismos o los familiares que los sobreviven, cuestión a la que luego se suma un determinado partido político y sus adherentes, con o sin animas de instrumentalización.
} 
Bonet Correa, Antonio, Fiesta, poder y arquitectura. Aproximaciones al barroco español, Madrid, Ediciones Akal, 1990.

Celis, Susana, Rebeldia y utopia, castigo y represión. Politicas Represivas en el Primer Gobierno de la Concertación, Profesor Guía: Hugo Godoy León. Reportaje para optar al Título de Periodista. Santiago, Facultad de Humanidades, Escuela de Periodismo, Universidad de Santiago de Chile, 2010.

Faure, Eyleen, Los locos del poder: aproximación histórica a la experiencia del Movimiento Juvenil Lautaro (19821997), Santiago, Pukayana Editorial, 2006.

Garavaglia, Juan Carlos, Construir el estado e inventar la nación. El Río de la Plata, siglos XVIII-XIX, Buenos Aires, Prometeo Libros, 2007.

Kinloch, Frances, Política y cultura en la transición al Estado- Nación, Nicaragua (1838-1858). Tesis de Maestría Académica en Historia. Costa Rica, Universidad de Costa Rica, 1999.

Lira, Elizabeth y Loveman, Brian, Las ardientes cenizas del olvido: Via chilena de Reconciliación Politica 19321994, Santiago, LOM Ediciones, 2000.

Lira, Elizabeth y Loveman, Brian, El espejismo de la reconciliación politica. Chile 1990-2002, Santiago, LOM Ediciones, 2002.

Lira, Elizabeth y Loveman, Brian, Políticas de reparación. Chile 1990-2004, Santiago, LOM Ediciones, 2005.

Ozouf, Mona, Festivals and the French Revolution, traducción de Alan Sheridan, Massachusetts, Harvard University Press, 1991.

Pozzi, Pablo y Pérez, Claudio (eds.), Historia oral e historia política. Izquierda y lucha armada en América Latina, 1960-1990, Santiago, LOM Ediciones, 2012.

Rivière, Claude, Les Liturgies politiques, París, Presses Universitaires de France, 1988.

Rosas, Pedro, Rebeldía, subversión y prisión politica. Crimen y castigo en la transición chilena 1990-2004, Santiago, Editorial Septiembre Negro, 2010.

Rousso, Henry, La última catástrofe. La historia, el presente, lo contemporáneo, Santiago, Editorial Universitaria, 2018.

Soto, Ángel, El presente es historia, Santiago, Centro de Estudios Bicentenario, 2006.

Zapata, Victoria, Cárcel de alta seguridad. Inhumanidad, represión y rebeldia, Santiago, Editorial Mare Nostrum, 2005.

Wilentz, Sean (ed.), Rites of Power: Symbolism, Ritual, and Politics since the Middle Ages, Pittsburgh, University of Pennsylvania Press, 1985. 


\section{Artículos y/o capítulos de libros:}

Aróstegui, Julio, "Historia y Tiempo Presente. Un nuevo horizonte de la historiografía contemporaneista", Cuadernos de Historia Contemporánea, 20, Madrid, 1998, 15-18.

Aróstegui, Julio, “La historia del presente, ¿Una cuestión de método?”, Carlos Navajas Zubeldia (ed.), Actas del IV Simposio de Historia Actual, Logroño, 17-19 de octubre de 2002, Gobierno de La Rioja, Instituto de Estudios Riojanos, Logroño, 2004, 41-75.

Bédarida, François, "Definición, método y práctica de la Historia del Tiempo Presente", Cuadernos de Historia Contemporánea, 20, Madrid, 1998, 19-27.

Cabrera, Luis, "Efectos de la impunidad en el sentido de justicia", Psicología Política, 23, Valencia, 2001, 37-58.

Chiaramonte, José Carlos, "Formas de identidad en el Río de la Plata luego de 1810", Boletín del Instituto de Historia Argentina y Americana "Dr. Emilio Ravignani", 3ra Serie, 1, Buenos Aires, 1er semestre de 1989, 71-92.

Cuesta, Josefina, "La historia del tiempo presente: estado de la cuestión", Studia Historica. Historia Contemporánea, 1, Salamanca, 1983, 227-241.

Del Río Sánchez, Ángel y Talego Vázquez, Félix, "Impugnando la impunidad. Las víctimas del franquismo frente al Estado", Periferias, fronteras y diálogos. Actas del XIII Congreso de Antropología de la Federación de Asociaciones de Antropología del Estado Español, Tarragona, Universitat Rovira i Virgili, 2014, 3151-3173

Díaz, Diego, "La Historia del Tiempo Presente. Breve revisión a la disciplina del estudio histórico de las dinámicas de la sociedad actual", Revista Abordajes, 1:2, La Rioja, segundo semestre 2013, 5-29.

Duncan, Robert H., "Embracing a Suitable Past: Independence Celebrations under Mexico's Second Empire, 1864-1866", Journal of Latin American Studies, Cambrigde, 30, mayo de 1998, 249-277.

Fazio, Hugo, "La historia del tiempo presente: una historia en construcción”, Historia Crítica, 17, Bogotá, julio-diciembre 1998, 47-57.

Fumero, Patricia, "De la iniciativa individual a la cultura oficial. El caso del General José Dolores Estrada. Nicaragua, década de 1870", Kinloch, Frances (ed.), Nicaragua en busca de su identidad, Managua, Instituto de Historia de Nicaragua y Centroamérica, Universidad Centroamericana, 1995, 307-349.

Garretón, Manuel Antonio, "La cuestión del régimen de gobierno en el Chile de hoy", Lanzaro, Jorge (comp.), Tipos de presidencialismo y coaliciones politicas en América Latina, Buenos Aires, CLACSO, 2001, 189202.

Kinloch, Frances, "Fiestas patrias: tradición y realidad (Nicaragua, 1858)", Vannini, Margarita y Kinloch, Frances (eds.), Politica, cultura y sociedad en Centroamérica. Siglos XVIII-XX, Managua, Instituto de Historia de Nicaragua y Centroamérica, Universidad Centroamericana, 1998, 83-92. 
Monsálvez, Danny, "La dictadura militar de Augusto Pinochet como Historia del Presente: historiografía, dictadura, transición, demanda social y crisis de representatividad", Historia Actual Online, 30, Cádiz, invierno 2013, 175-191.

Ortemberg, Pablo, "Sentidos e historia de las fiestas patrias: una introducción", Ortemberg, Pablo (dir.), El origen de las fiestas patrias. Hispanoamérica en la era de las independencias, Rosario, Prohistoria Ediciones, 2013, $11-42$.

Rioux, Jean-Pierre, "Historia del Tiempo Presente y demanda social", Cuadernos de Historia Contemporánea, 20, Madrid, 1998, 71-81.

Sandoval, Irma, "Enfoque de la corrupción estructural: poder, impunidad y voz ciudadana", Revista Mexicana de Sociologia, 78:1, Ciudad de México, enero-marzo 2016, 119-152.

Sauvage, Pierre, "Una historia del tiempo presente", Historia Crítica, 17, Bogotá, julio-diciembre 1998, 5970.

Schneider, Cecilia y Avenburg, Karen, "Cultura política: un concepto atravesado por dos enfoques", Post Data, 20:1, Buenos Aires, junio de 2015, 109-131.

Soto, Ángel, “Historia del presente: estado de la cuestión y conceptualización”, Historia Actual Online, 3, Cádiz, invierno 2004, 101-116.

Thomson, Gyu P.C., "Bulwarks of Patriotic Liberalism: The National Guard, Philharmonic Corps and Patriotic Juntas in Mexico, 1847-88", Journal of Latin American Studies, Cambridge, 22:1-2, febrero de 1990, $31-68$.

Peter Winn, “El pasado está presente. Historia y memoria en el Chile contemporáneo”, Pérotin-Dumon, Anne (dir.), Historizar el pasado vivo en América Latina, Santiago, Universidad Alberto Hurtado, Centro de Ética, 2007, 1-48.

\section{Publicaciones periódicas:}

“Actitud de Socialistas es peligrosa”, Las Últimas Noticias, Santiago, 27 de junio de 1990, 3.

Aranguiz, Carolina, "La democracia cobra primera víctima”, El Siglo, Santiago, 30 de junio de 1990, 1 y 13-15.

Badilla, Iban, "Comisión Rettig. Encontrarse con la verdad", Análisis, Santiago, N 337, 25 de junio a 1 de julio de 1990, 10-11.

"Belisario Velasco asistió a funerales de joven comunista", Las Últimas Noticias, Santiago, 30 de junio de 1990, 15.

"Carabineros dio de baja a 3 policías por muerte de muralista del PC", La Segunda, Santiago, 28 de junio de 1990, 3 .

“Carabineros: No han sido dados de baja 3 oficiales”, La Segunda, Santiago, 2 de julio de 1990, 18. 
Corporación de Promoción y Defensa de los Derechos del Pueblo (CODEPU), Informe Derechos Humanos. 1990-1994, Santiago, abril de 1994.

"De baja 3 carabineros por baleo a muralista", La Tercera, Santiago, 29 de junio de 1990, 6.

“Dieron de baja a tres carabineros”, Las Últimas Noticias, Santiago, 29 de junio de 1990, 17.

"Dos años a carabinero que mató de balazo a joven muralista en Lo Sierra", La Cuarta, Santiago, 4 de agosto de 1994, 4.

"Esta tarde son funerales de brigadista de JJ.CC.”, La Tercera, Santiago, 29 de junio de 1990, 6.

"Emotivos funerales del muralista de las JJ.CC.", La Tercera, Santiago, 30 de junio de 1990, 6.

“Entregan los bienes de familia Allende Bussi”, La Tercera, Santiago, 27 de junio de 1990, 14.

“Ex ministros rindieron su homenaje a Allende", Las Últimas Noticias, Santiago, 28 de junio de 1990, 3.

"Fiscal reconstituyó baleo", La Tercera, Santiago, 29 de junio de 1990, 6.

"Frente Lautaro atacó con fuego de metralletas un furgón de Carabineros: dos heridos", La Segunda, Santiago, 4 de julio de 1990, 2.

“Gobierno lamentó hechos”, La Tercera, Santiago, 29 de junio de 1990, 6.

“Investigan muerte de un militante de las JJ.CC.”, La Tercera, Santiago, 28 de junio de 1990, 25.

"La sangre regó la noche", La Semana Grafica (Suplemento de Las Últimas Noticias), Santiago, 1 de julio de 1990,5 .

Martorell, Francisco, "Los cien días de Aylwin", Análisis, Santiago, N 337, 25 de junio a 1 de julio de 1990, 9 .

“Muere joven comunista”, Análisis, Santiago, № 338, 2 al 8 de julio de 1990, 23.

"Muralista de Juventudes Comunistas murió baleado", Las Últimas Noticias, Santiago, 28 de junio de 1990, 18.

"Oficiales de Carabineros no han sido dados de baja", La Tercera, Santiago, 3 de julio de 1990, 6.

"Pendiente fallo sobre 'Caso Quemados”, La Segunda, Santiago, 28 de junio de 1990, 4.

“¿Qué miedos tienen los chilenos?”, La Segunda, Santiago, 13 de marzo de 1992, 34-37.

"Tres años para carabinero que mató a muralista en Lo Espejo", La Cuarta, Santiago, 10 de noviembre de 1995,7 .

“Tres oficiales de baja por baleo a muralista”, La Tercera, Santiago, 2 de julio de 1990, 4. 
Vásquez Muruaga, Luciano, “Los primeros cien días”, Las Últimas Noticias, Santiago, 28 de junio de 1990, 9 .

\section{Archivo:}

"Expediente Caso Osman Yeomans", Santiago, Centro de Documentación del Museo de la Memoria y los Derechos Humanos.

\section{Entrevistas:}

Entrevista con Hiram Villagra, Santiago, mayo de 2010.

Entrevista con Sandra Jiménez Rodríguez, Santiago, 7 de mayo de 2018. 